\title{
Influencing Factors of Innovation and Entrepreneurship Education Based on the Theory of Planned Behavior
}

\author{
https://doi.org/10.3991/ijet.v15i13.15345 \\ Lin Ma $\left({ }^{凶}\right)$, Zhuangzhuang Lan, Ru Tan \\ Baoji University of Arts and Sciences, Baoji, China \\ bywind1999@126.com
}

\begin{abstract}
In the pursuit of "Mass Entrepreneurship and Innovation", many colleges have opened a new course called Innovation and Entrepreneurship. However, the existing studies on innovation and entrepreneurship (IE) education mainly focus on education reform, failing to tackle the cultivation of IE spirit among college students. To make up for the gap, this paper firstly introduces the theory of educational psychology and the theory of planned behavior (TPB), and summarizes the status quo of the IE education in developed countries (e.g. the US, the UK and Japan) and developing countries (e.g. China). Next, the influencing factors of the entrepreneurial intention of college students were modelled based on the TPB, and a questionnaire survey on the correlation between the influencing factors and the entrepreneurial intention was conducted among college students in Baoji University of Arts and Sciences. The survey results were imported to our model, and subjected to computations on Amos 26.0, maximum likelihood estimation and standardized analysis. The results show that the entrepreneurial intention has a significant positive correlation with the attitude toward the IE and the perceived behavioral control, and an insignificant positive correlation with the subjective norms; the entrepreneurial intention of college students is directly affected by social impacts, in addition to school education; the IE education should pay attention to the practical experience of college students. The research results provide a good reference to the cultivation of IE spirit among college students.
\end{abstract}

Keywords - The theory of planned behavior (TPB), innovation and entrepreneurship (IE) education, influencing factors, teaching strategies

\section{$1 \quad$ Introduction}

The IE education among college students is an important part of the China's higher education and a comprehensive reflection of quality education. It consists of both over-generalized innovation and practical entrepreneurship. The contents of innovation and entrepreneurship are essentially correlated; innovation is the precursor and foundation of entrepreneurship, while entrepreneurship is the carrier and manifestation of innovation, and the success or failure of entrepreneurship depends on the degree of innovation. Therefore, the IE education is largely coincident, with the same goal orientation of cultivating the IE spirit [1]. In today's society, the innovation- 
driven economic development has become an important strategic means for various countries in the world. Thus, in the era with college students as the main talent reserve, efforts must be strengthened to the IE for college students and improve their IE skills.

After reviewing the research on IE education by scholars from various countries, it is found that the IE development plays a very important role in national strategic development, social and economic development, and personnel training. In terms of national strategy, in June 2010, the CPC Central Committee and the State Council proposed a strategic plan to vigorously cultivate talents and entrepreneurs; scholars Yuan Jinxiang and Jiang Guanjun pointed out that the development of entrepreneurship education is an inevitable requirement for building an innovative country. In terms of national economic development, the IE education for college students meets the current requirements of economic development driven by innovation. Chinese President Xi Jinping once stated that "development is the top priority and innovation is the primary driver." College students are the backbone of talent reserves. IE education can significantly enhance the innovation power of the entire society. Meanwhile, in the current entrepreneurial era, the IE education can cultivate the college students' entrepreneurship, and further enhance the core competitiveness of the entire country through independent innovation, transformation of scientific and technological achievements, and job creation. This shall promote industrial upgrading, economic structure optimization, and the formation of new economic growth [2]. Gordon et al. [3] also showed that entrepreneurship education has brought a series of economic benefits to small and medium-sized enterprises and regions. In terms of talent training, the IE education is an effective way to enhance the creativity and train innovative spirit of college students. By studying the basic IE courses, students can make full use of their strengths and hobbies, and choose their own entrepreneurial goals even in a new entrepreneurial environment. This can also help them to improve themselves comprehensively, realize their own value, and accurately find the direction and goal suitable for future development. Clues [4] also pointed out that entrepreneurship education plays a decisive role in the start-up of college students so that they can cope with the difficulties and challenges in the early stage of entrepreneurship, and it can help students to establish a timely awareness of risks.

At present, the research on IE education of Chinese college students mainly focuses on the reform of the education model. Cultivation of IE spirit among college students is the key to the successful implementation of IE education. But there has been very little research in this aspect. From the perspective of educational psychology, this paper takes college students of Baoji University of Arts and Sciences in China as the research objects, establishes a TPB theoretical model, and then explore the cultivation of IE spirit for college students. This shall contribute to the better development of IE education among college students in the future. 


\section{Theoretical Research Basis for IE Education of College Students}

\subsection{Educational psychology theory}

The development of educational activities is inseparable from the educational psychology knowledge. The IE of college students, as a manifestation of quality education, also requires the guidance of educational psychology. The educational activities are to cultivate the IE ability of college students and enhance their quality in all aspects. This determines the universality of the IE content for college students. Thus, it is of great significance for the integration of education psychology knowledge into college IE education [5].

Meanwhile, IP education aims to develop the creativity of college students. Educational psychology points out that creativity is the psychological characteristics of individuals using certain internal and external conditions to produce novel, unique, social and personal value products. Similar to other psychological qualities of human beings, it is also gradually formed and developed through the acquired environment, education and continuous creative practice activities of individuals on the basis of innate genetics, following the maturity of individual physiology, and its development reaches peak at the age of 20-40 years of individuals. Therefore, creative development also has certain age characteristics. College students are at a key period for creative development. So, the full use of the creative development characteristics of college students plays a very important role in the development of their IE education.

\section{$2.2 \quad$ TPB theory}

TPB theory, the abbreviated form of the theory of planned behavior, was researched by the American psychologist Ajzen. According to this theory, all elements that affect an individual's certain behavior must indirectly act on the behavior itself by the intention, while behavior attitude, subjective norms and perceived behavioral control are the main factors affecting behavioral intention, namely Theory of Planned Behavior [6], as shown in Fig. 1.

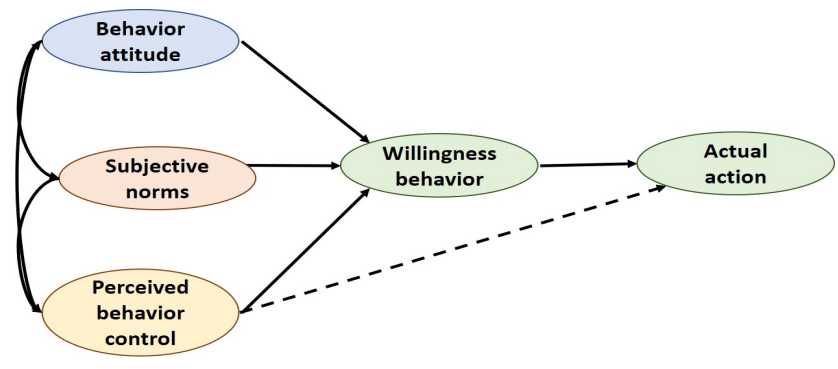

Fig. 1. Original model of TPB theory 
The TPB is a measurement model that reflects intention to behavior. As a wellknown theoretical model for predicting and explaining the relationship between attitude and behavior in social psychology, it has been widely used in many fields of human life [7]. The TPB theory generally means: the more positive the individual's attitude towards a certain practical behavior, the stronger the intention; the more positive the individual's subjective norms for a certain behavior, the stronger the individual's intention to behave; the better individual's perception of certain behavior control, the stronger the intention to behave [8]. And since Ajzen put forward the theoretical model, more and more research and application of the model have been carried out, bringing a richer connotation to this theory. Starting from three dimensions, the exploration and research of college students' IE education is also quite rich. As far as behavioral attitudes are concerned, Tyler et al. believed that individual attitudes are not fixed, and they will change with their experiences, lives, etc. [9], so the IE education for college students will make them form a positive attitude towards the IE. Qi and Liu [10] also found in their study that entrepreneurial attitude has the most obvious influence on entrepreneurial intention; In terms of subjective norms, Krueger et al. [11] studied the impact of subjective norms on IE intentions and concluded that the groups or individuals that have greater impact on individual behavior, such as parents, teachers, relatives and friends, and special role models, should be selected to improve the explanatory power of subjective norms on entrepreneurial intention. Some research in China also proves that compared with the impact of social groups on individual entrepreneurial intention, individual students are more susceptible to the influence of peers and alumni around them, that is, entrepreneurial intention has an obvious "aggregation effect" [12]. In terms of perceived behavioral control, Brenner et al. [13] taking students from a university in the eastern United States as the research object, found in their study that there is a significant difference between the entrepreneurial intentions of college students under unconditional constraints and that considering their own circumstances and objective reality, and the former entrepreneurial intention is much higher than the latter. Through the survey of college students in Guangzhou, Mo [14] also found that only the perceived behavioral control directly affects the entrepreneurial intention of the individual, and the entrepreneurial attitudes affect entrepreneurial intention by perceived behavioral control.

Through the analysis of the above, it can be found that in the research on the impact of IE intention, the results of entrepreneurial intention vary from three dimensions, but they all have a certain positive explanation, indicating the formation of IE intention motivation and behavior is related to people's internal drive rather than external non-self feelings. Therefore, the authors, based on the analysis of the above research and the original model of the TPB theory, started from the relevant perceptual factors of college students, modeled the influencing factors of entrepreneurial intention for college students, and analyzed the impact accordingly. 


\section{The Status Quo of College Students' IE Education}

IE education has a history of more than 70 years. The IE concept was originated in the US in the 1980s. The American economist Schumpeter proposed the concept of innovation in 1912. The entrepreneurship education was formally put forward at the 1989 "International Conference on Education for the 21st Century". At the international level, UNESCO first mentioned the concept of the "third education passportentrepreneurship education" at the seminar on Education for the 21st Century held in 1989. Afterwards, its Declaration on Higher Education in the 21st Century also emphasized that higher education should pay more attention to the cultivation of students' entrepreneurial skills and spirit. This series of policy documents has well guided the development of IE education.

\subsection{Current status of IE education in the US, UK and Japan}

The implementation of IE education among college students can be traced back to the establishment of the New Enterprise Management course by Professor Michael Metz of Harvard Business School in 1947, which focused on teaching entrepreneurial experience to MBA students. At present, with the increase in the IE importance, many countries around the world have been vigorously implementing the IE education, especially the developed countries such as the US, the UK, and Japan.

The United States is the first to carry out the IE education. It has undergone from the initial theoretical exploration to the gradual application of practical models. Today, entrepreneurship education has become the fastest growing academic field in the US higher education community. The educational model mostly adopts the dualteacher system, using social entrepreneurs and school teachers for bilateral teaching. There are many entrepreneurial centers linked to the society, providing students with complete hardware conditions for IE, so that students can really get in touch with enterprises in the society, understand entrepreneurs' thoughts, and learn to use entrepreneurs' thinking. In the curriculum construction, entrepreneurship education has become one of the fastest-growing disciplines in American undergraduate courses, which reflects the strong vitality of the IE development.

Compared with the US in the IE education, UK has a late start, but develops rapidly. It has changed from an early utilitarian education model to an education model that focuses on the cultivation of IE awareness in college students and also the industryuniversity-research integrated education. As early as 1982, the UK followed the IE pace of American college students, set up a "college student entrepreneurship" project, started college IE education, and encouraged college graduates to find employment in local areas and try to start their own businesses, thereby achieving selfemployment and creating more jobs. This has set a good foundation for the IE practice among college students. In 2004, the UK established the National College Students Entrepreneurship Committee that provided consulting and guidance services for college students [15], indicating that the UK government attaches great importance to the IE education of college students. 
Japan is a relatively mature country in IE education in Asia. The Basic Law on Science and Technology promulgated in 1995 greatly promoted the development of IE education. By 2005, it had successfully transformed from utilitarian education to entrepreneurship education focusing on spiritual cultivation. Also, like the US, Japanese university actively encourages teachers to cooperate with enterprises; considering that entrepreneurship education has a strong coherence, there is an IE education course for both middle school students and university students, forming a typical government-led IE education model.

\subsection{Current status of China's IE education}

China's IE education started relatively late, but it has developed rapidly. Since the Action Plan for Education Rejuvenation for the 21st Century formulated in 1998 proposed the entrepreneurship education for the first time, entrepreneurship education has been carried out successively in major universities in China [16]. With the deepening of education reform, more emphasis has been laid on IE education, and there are more and more diversified researches on IE, as shown in Fig. 2. From the figure, the IE research not only includes the cultivation of talents in higher education, but also the practical exploration and further the management of IE enterprises and talents. It shows an IE-dominated divergent type, indicating that China's research in IE education is developing rapidly, which also provides strong theoretical support for our research.

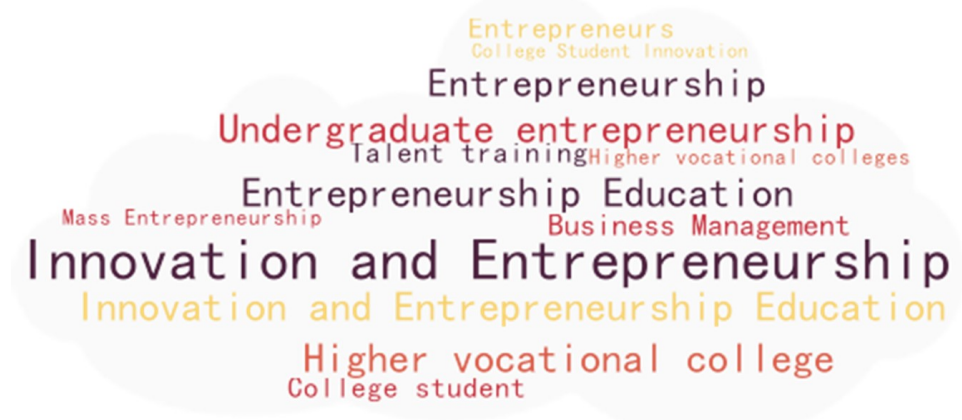

Fig. 2. Word cloud analysis for the current status of IE education research

From the perspective of the development history of China's IE education, it has now been more than 20 years, since the first IE competition organized by Tsinghua University in 1998, In these years, it has also developed some systematic IE practice modes such as the innovation and entrepreneurship incubation center, and Makerspace etc., and the most notable is the construction of college students' IE courses and Innovation and Entrepreneurship competitions. The types of IE Competition mainly include Challenge Cup, Internet+ Innovation and Entrepreneurship Competition, and China IE competition, etc. The competition system is divided into three 
levels: school, province and autonomous region, and the nation. The form of competitions can help to gradually realize the landing of college students' IE education, and truly and effectively combine the theory and practice, thereby achieving the purpose of educating people.

From the perspective of China's IE education research, on China HowNet, there are more than 19,000 documents on the theme of "Innovation and Entrepreneurship", and more than 14,000 documents on the "IE Education", but only more than one thousand documents on the theme of "College Students' IE Education", and very fewer on the "Cultivation of College Students' Innovation and Entrepreneurship". This indicates that China's research on IE education has generally formed a certain research trend, but little research is conducted on the cultivation of IE spirit in college students, which is still in the early stages of exploration, as shown in Fig. 3. For example, Jia Haiyan found in the survey results of college students' entrepreneurial intentions, entrepreneurial action, self-entrepreneurial quality, and entrepreneurial cognition that most college students have entrepreneurial intentions and more aware of entrepreneurial cognition and self-entrepreneurial quality, but weak in entrepreneurial action. In terms of external environmental impact, Liu Baozhong concluded the problems with the IE cultivation environment such as the insufficient faculty, the backward training concept, lack of a practical platform, the backward training methods, and the ineffective training. It can be seen that China's research on college students' IE education focuses more on the exploration and transformation of college education models, education systems, and education implementation, but not involving much about the students themselves, and the development and improvement of student's quality. Therefore, the authors went deep in thinking and exploring in this direction.

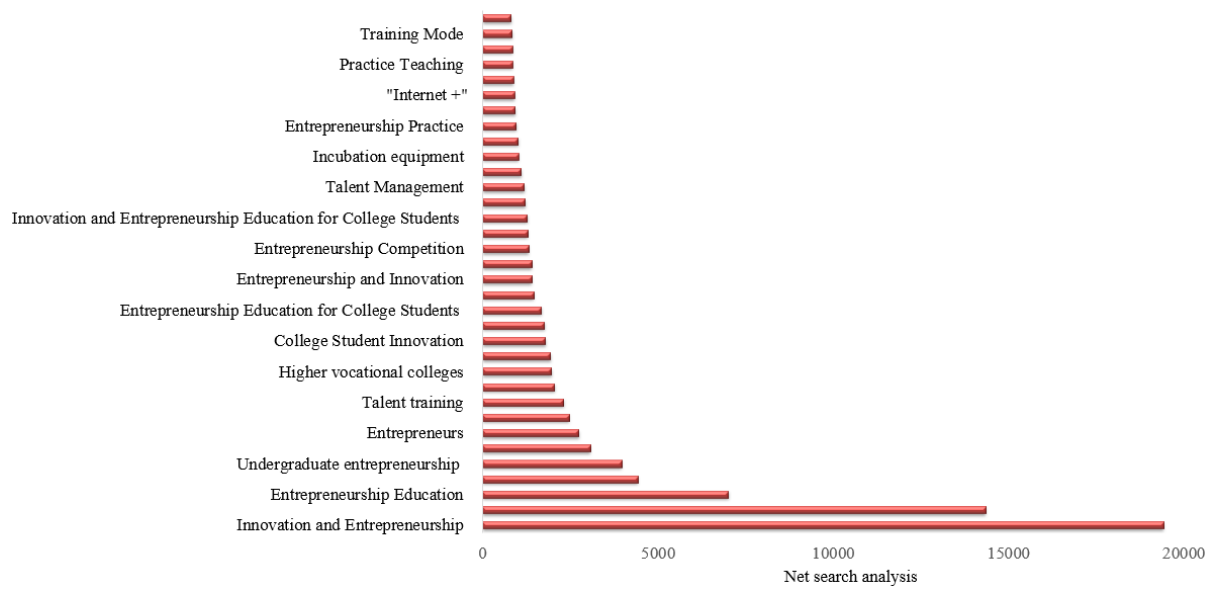

Fig. 3. How Net search analysis

From the perspective of the IE practice, the statistics analysis was conducted on the data of 2016-2019 Chinese college students' IE projects, as shown in Table 1. From the table, the following information was obtained: 
1. The number of China's IE projects has a certain correlation with the regional economic development; the number of China's college student entrepreneurship projects have reached 1,112.680; the number of entrepreneurship projects in western China is 325,006 , accounting for $29.2 \%$ of the total, less than one-third, while that of entrepreneurial projects in eastern China is 450,446, accounting for $40.5 \%$

2. The IE projects is still mainly implemented in China, and few are in other countries, i.e., only 62 , accounting for only $0.0056 \%$ of the total Chinese entrepreneurial projects

3. IE projects transformed by scientific research achievements in Chinese universities are generally considerable, accounting for $45.6 \%$ of the total number in China

4. IE projects are rarely financed, and the total number of unfinanced IE projects reaches $99.8 \%$ of the total number of IE projects in China, which also indicates great difficulty for the project to realize the transformation of project results. To sum up, China should increase investment in economy and technology for the IE competition, focus on a global perspective, and build the international influence of China's IE competition. The IE competition should not only focus on the number of IE projects, but also the transformation of the IE project results.

Table 1. The number, regional distribution and percentage of college students' entrepreneurial projects 2016-2019 [17]

\begin{tabular}{|l|c|c|}
\hline \multicolumn{1}{|c|}{ Project Type } & Quantity & Percentage \\
\hline Total number of entrepreneurial projects in China & 1112680 & $100 \%$ \\
\hline Total number of entrepreneurial projects in countries other than China & 62 & $0.0056 \%$ \\
\hline Total number of entrepreneurial projects in Western China & 325006 & $29.2 \%$ \\
\hline Total number of entrepreneurial projects in eastern China & 450446 & $40.5 \%$ \\
\hline $\begin{array}{l}\text { Total number of scientific research achievement transformation projects in } \\
\text { Chinese universities }\end{array}$ & 507004 & $45.6 \%$ \\
\hline Number of unfinanced entrepreneurial projects & 1110559 & $99.8 \%$ \\
\hline
\end{tabular}

By analyzing the current status of IE education in multiple countries, it can be found that the reform of China's IE education focuses on the education model and talent training. The US, the UK, and Japan emphasize on how to integrate the educational process into the social enterprise environment, pay more attention to the transformation of educational concepts, and cultivate entrepreneurial spirits.

\section{Cultivation of the IE Spirit Among College Students}

\subsection{Model establishment and object selection}

Fig. 4 shows the influencing factors of the entrepreneurial intention based on the TPB theoretical model. It can be seen from the above that the purpose of college students' IE education is to train students with independent thinking and practical ability. Based on the relationship between innovation and entrepreneurship, and their respective characteristics and evaluability, this study measures the ultimate behavior, that is, the generation of entrepreneurial behavior. Therefore, the model should be designed 
to reflect the four measurement indicators of entrepreneurial attitude, subjective norms, perceived behavioral control, and entrepreneurial intention generated by behavior, and analyze the structural model using Amos26.0 software to achieve the relationship between final data explaining variables and generated behavior.

In terms of object selection, this study selected the college students of Baoji University of Arts and Sciences as the research objects. A survey was conducted on the IE education in Baoji College of Arts and Sciences. It's found that this college has achieved certain results and gained some experience in the construction and practice of IP courses, responding to the Chinese call upon "Innovation and Entrepreneur". Students were exposed to the basic courses of innovation and entrepreneurship since the first year of school, and 11 school-level IE teams have been established to ensure the scientificity and representativeness of the data collected by the questionnaire.

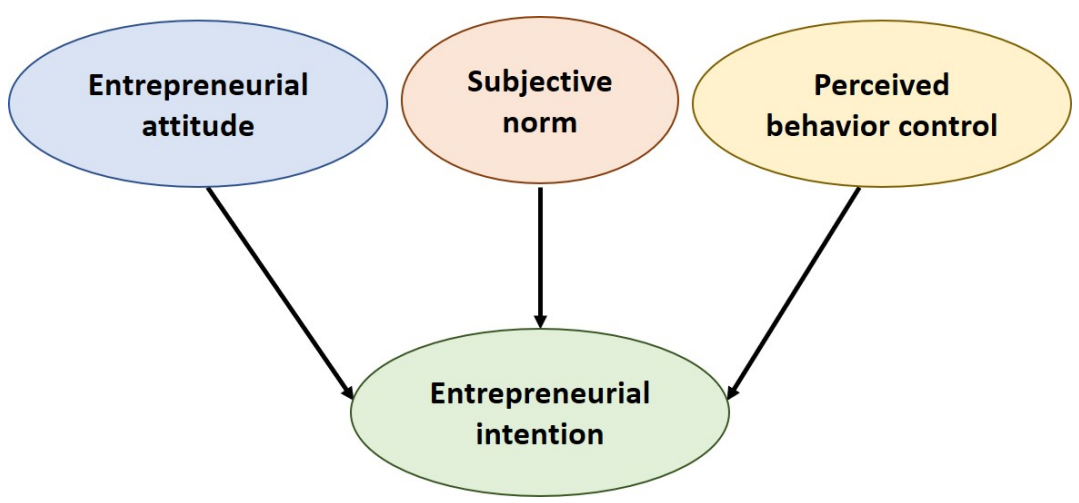

Fig. 4. Model of influencing factors of college students' entrepreneurial intention based on TPB theory

\subsection{Questionnaire design and sample selection}

The questionnaire was compiled with four latent variables: entrepreneurial attitudes, subjective norms, perceived behavioral control, and entrepreneurial intention; 21 observed variables were set to reflect the four latent variables, as shown in Table 2. A 5-level rating scale was used, i.e., completely disagree, relatively disagree, disagree, relatively agree, and completely agree, which were scored $1-5$, in order to analyze the effect on college students 'entrepreneurial intention.

The questionnaires were distributed in electronic form on the questionnaire network to the selected students of Baoji University of Arts and Science students. 542 questionnaires were recovered, and by eliminating the invalid questionnaires, a total of 469 valid questionnaires were collected. Meanwhile, in order to ensure the validity of the questionnaire data and statistical results, statistical software SPSS26.0 was adopted to analyze the reliability and structural validity of the questionnaire, as shown in Table 3. It can be seen from the table, the overall Cronbach's alpha coefficient of the IE questionnaire for college students were 0.901 . In addition, the reliability analysis of the four latent variables was carried out, to obtain the Cronbach's alpha coefficients of $0.775,0.806,0.739$, and 0.889 respectively, all of which were above 0.7 , 
indicating a good reliability of the questionnaire. In the structural validity test of the questionnaire about college students' awareness of IE, the statistical software SPSS26.0 was used for the maximum variance factor analysis. The results also showed that the standard factor load coefficient of each measured variable was basically above 0.6 , indicating that there is no obvious cross-factor phenomenon in each measurement index. Thus, the questionnaire has a clear design structure, strong purpose, and good structural validity.

Table 2. Distribution of measurement items for latent and observed variables [18]

\begin{tabular}{|c|c|}
\hline Latent variables & Observed variables \\
\hline \multirow{5}{*}{$\begin{array}{l}\text { Entrepreneurial } \\
\text { attitudes }\end{array}$} & $\begin{array}{l}\text { Q1: Innovation and entrepreneurship have brought me more benefits than disad- } \\
\text { vantages. }\end{array}$ \\
\hline & $\begin{array}{l}\text { Q2: If I become an innovative entrepreneur, it will bring me a sense of self- } \\
\text { satisfaction. }\end{array}$ \\
\hline & Q3: If I have the opportunity and resources, I want to start a company. \\
\hline & Q4: If I have many career choice possibilities, I want to start a company. \\
\hline & $\begin{array}{l}\text { Q5: I believe that if I have the opportunity to start a business, I will be confident to } \\
\text { prepare for it. }\end{array}$ \\
\hline \multirow{5}{*}{ Subjective norms } & $\begin{array}{l}\text { Q6: On the road of starting a business, I would be easier under the support of my } \\
\text { family. }\end{array}$ \\
\hline & $\begin{array}{l}\text { Q7: On the road of starting a business, I would be easier under the support of my } \\
\text { friends. }\end{array}$ \\
\hline & $\begin{array}{l}\text { Q8: On the road of starting a business, it would be easier under the support of my } \\
\text { colleagues. }\end{array}$ \\
\hline & $\begin{array}{l}\text { Q9: The current social environment and policies will have a great impact on my } \\
\text { entrepreneurship. }\end{array}$ \\
\hline & Q10: I think innovation will have a positive effect on my entrepreneurship. \\
\hline \multirow{4}{*}{$\begin{array}{l}\text { Perceived behavioral } \\
\text { control }\end{array}$} & Q11: It is very difficult for me to start a company and maintain the operation. \\
\hline & Q12: I can control the whole establishment process of company. \\
\hline & $\begin{array}{l}\text { Q13: I know about the implementation steps for the application of innovation and } \\
\text { entrepreneurship to the establishment of the company. }\end{array}$ \\
\hline & $\begin{array}{l}\text { Q14: I think the motivation of innovation and entrepreneurship is greatly affected by } \\
\text { the external environment }\end{array}$ \\
\hline \multirow{7}{*}{$\begin{array}{l}\text { Entrepreneurial } \\
\text { intention }\end{array}$} & Q15: My career goal is to be an entrepreneur. \\
\hline & Q16: I will make every effort to start a business if I have an entrepreneurial idea. \\
\hline & Q17: I am determined to start a business in the future. \\
\hline & Q18: With policy support, I will choose to start a business. \\
\hline & Q19: Entrepreneurship can satisfy my continuously innovative ideas. \\
\hline & Q20: I will innovate in my professional field. \\
\hline & $\begin{array}{l}\text { Q21: If innovation can enhance my personal social experience, I will be willing to } \\
\text { innovate. }\end{array}$ \\
\hline
\end{tabular}


Paper-Influencing Factors of Innovation and Entrepreneurship Education Based on the Theory of ...

Table 3. Analysis for reliability and structure validity of the questionnaire

\begin{tabular}{|c|c|c|c|c|c|}
\hline Latent variable & Measured variable & number & Standard factor load & Cronb & ch coefficient \\
\hline \multirow{5}{*}{$\begin{array}{l}\text { Entrepreneurial atti- } \\
\text { tude }\end{array}$} & Q1 & \multirow{5}{*}{5} & 0.786 & \multirow{5}{*}{0.775} & \multirow{5}{*}{ 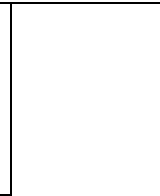 } \\
\hline & Q2 & & 0.795 & & \\
\hline & Q3 & & 0.793 & & \\
\hline & Q4 & & 0.781 & & \\
\hline & Q5 & & 0.653 & & \\
\hline \multirow{5}{*}{ Subjective norm } & Q6 & \multirow{5}{*}{5} & 0.839 & \multirow{5}{*}{0.806} & \multirow{16}{*}{0.901} \\
\hline & Q7 & & 0.857 & & \\
\hline & Q8 & & 0.855 & & \\
\hline & Q9 & & 0.760 & & \\
\hline & Q10 & & 0.597 & & \\
\hline \multirow{4}{*}{$\begin{array}{l}\text { Perceived behavior } \\
\text { control }\end{array}$} & Q11 & \multirow{4}{*}{4} & 0.835 & \multirow{4}{*}{0.739} & \\
\hline & Q12 & & 0.843 & & \\
\hline & Q13 & & 0.741 & & \\
\hline & Q14 & & 0.636 & & \\
\hline \multirow{7}{*}{$\begin{array}{l}\text { Entrepreneurial inten- } \\
\text { tion }\end{array}$} & Q15 & \multirow{7}{*}{7} & 0.688 & \multirow{7}{*}{0.889} & \\
\hline & Q16 & & 0.725 & & \\
\hline & Q17 & & 0.805 & & \\
\hline & Q18 & & 0.778 & & \\
\hline & Q19 & & 0.751 & & \\
\hline & Q20 & & 0.699 & & \\
\hline & Q21 & & 0.595 & & \\
\hline
\end{tabular}

\subsection{Results analysis}

Table 4. The standardized path of the theoretical structure equation model for college students' IE influencing factors

\begin{tabular}{|c|c|c|c|c|c|c|c|}
\hline $\begin{array}{c}\text { Latent / } \\
\text { measured } \\
\text { variable }\end{array}$ & & & Unestimate & Estimate & S.E. & C.R. & $\mathbf{P}$ \\
\hline $\begin{array}{l}\text { Entrepreneurial } \\
\text { intention }\end{array}$ & $<---$ & $\begin{array}{l}\text { Entrepreneurial } \\
\text { attitude }\end{array}$ & 1.237 & 0.583 & 0.177 & 7.003 & $* * *$ \\
\hline $\begin{array}{l}\text { Entrepreneurial } \\
\text { intention }\end{array}$ & $<---$ & Subjective norm & 0.095 & 0.084 & 0.048 & 1.981 & 0.048 \\
\hline $\begin{array}{l}\text { Entrepreneurial } \\
\text { intention }\end{array}$ & $<---$ & $\begin{array}{l}\text { Perceived behav- } \\
\text { ioral control }\end{array}$ & 0.231 & 0.304 & 0.036 & 6.463 & $* * *$ \\
\hline Q1 & $<---$ & $\begin{array}{l}\text { Entrepreneurial } \\
\text { attitude }\end{array}$ & 1.000 & 0.407 & & & \\
\hline Q2 & $<---$ & $\begin{array}{l}\text { Entrepreneurial } \\
\text { attitude }\end{array}$ & 1.023 & 0.413 & 0.163 & 6.281 & $* * *$ \\
\hline Q3 & $<---$ & $\begin{array}{l}\text { Entrepreneurial } \\
\text { attitude }\end{array}$ & 2.004 & 0.721 & 0.249 & 8.047 & $* * *$ \\
\hline Q4 & $<---$ & $\begin{array}{l}\text { Entrepreneurial } \\
\text { attitude }\end{array}$ & 2.449 & 0.805 & 0.296 & 8.274 & $* * *$ \\
\hline Q5 & $<---$ & \begin{tabular}{|l|} 
Entrepreneurial \\
attitude
\end{tabular} & 2.248 & 0.785 & 0.273 & 8.229 & $* * *$ \\
\hline Q6 & $<---$ & Subjective norm & 1.000 & 0.829 & & & \\
\hline Q7 & $<---$ & Subjective norm & 1.013 & 0.918 & 0.044 & 23.27 & $* * *$ \\
\hline
\end{tabular}




\begin{tabular}{|c|c|c|c|c|c|c|c|}
\hline Q8 & $<--$ & Subjective norm & 0.994 & 0.839 & 0.047 & 21.356 & $* * *$ \\
\hline Q9 & $<---$ & Subjective norm & 0.418 & 0.318 & 0.062 & 6.742 & $* * *$ \\
\hline Q10 & $<---$ & Subjective norm & 0.566 & 0.483 & 0.053 & 10.605 & $* * *$ \\
\hline Q11 & $<---$ & $\begin{array}{l}\text { Perceived behav- } \\
\text { ioral control }\end{array}$ & 1.000 & 0.819 & & & \\
\hline Q12 & $<---$ & $\begin{array}{l}\text { Perceived behav- } \\
\text { ioral control }\end{array}$ & 0.956 & 0.870 & 0.058 & 16.48 & $* * *$ \\
\hline Q13 & $<--$ & $\begin{array}{l}\text { Perceived behav- } \\
\text { ioral control }\end{array}$ & 0.796 & 0.641 & 0.058 & 13.712 & $* * *$ \\
\hline Q14 & $<---$ & $\begin{array}{l}\text { Perceived behav- } \\
\text { ioral control }\end{array}$ & 0.196 & 0.247 & 0.039 & 5.007 & $* * *$ \\
\hline Q15 & $<---$ & $\begin{array}{l}\text { Entrepreneurial } \\
\text { intention }\end{array}$ & 1.000 & 0.711 & & & \\
\hline Q16 & $<---$ & $\begin{array}{l}\text { Entrepreneurial } \\
\text { intention }\end{array}$ & 0.895 & 0.723 & 0.061 & 14.612 & $* * *$ \\
\hline Q17 & $<---$ & $\begin{array}{l}\text { Entrepreneurial } \\
\text { intention }\end{array}$ & 1.070 & 0.820 & 0.065 & 16.453 & $* * *$ \\
\hline Q18 & $<---$ & $\begin{array}{l}\text { Entrepreneurial } \\
\text { intention }\end{array}$ & 0.928 & 0.749 & 0.061 & 15.131 & $* * *$ \\
\hline Q19 & $<---$ & $\begin{array}{l}\text { Entrepreneurial } \\
\text { intention }\end{array}$ & 0.906 & 0.737 & 0.061 & 14.899 & $* * *$ \\
\hline Q20 & $<---$ & $\begin{array}{l}\text { Entrepreneurial } \\
\text { intention }\end{array}$ & 0.807 & 0.655 & 0.061 & 13.286 & $* * *$ \\
\hline Q21 & $<---$ & $\begin{array}{l}\text { Entrepreneurial } \\
\text { intention }\end{array}$ & 0.589 & 0.547 & 0.053 & 11.129 & $* * *$ \\
\hline
\end{tabular}

After collecting the data of the questionnaire, Amos26.0 software was used to perform model structure calculation, and the maximum likelihood estimation method was adopted to carry out standardized analysis. The results are shown in Table 4 and Fig. 5. It can be seen from the table that the three latent variables of entrepreneurial attitude, subjective norms, and perceived behavior control have a certain impact on entrepreneurial intention, and the standardized path coefficients Estimate were 0.583, 0.084 , and 0.304 , respectively, indicating the three latent variables have a positive correlation with entrepreneurial intention, especially the entrepreneurial attitudes and perceptual behavior control, but subjective norms has no significant effect.

Through the analysis for the effect of measured variables on latent variables, it can be seen that the measured variables of entrepreneurial attitudes have a very significant influence, ranked as Q4 (0.805), Q5 (0.785), Q3 (0.721), Q2 (0.413), and Q1 (0.407) according to weights. This indicates that in terms of entrepreneurial attitudes, the college students' psychological cognition of achievements is positively correlated with the entrepreneurial attitude. The measured variables of subjective norms have a significant difference in the degree of influence on the subjective norms, and the ones with more significant influence is Q7 (0.918), Q8 (0.839), Q6 (0.829), while the ones with weaker impact are Q10 (0.483), Q9 (0.318). 


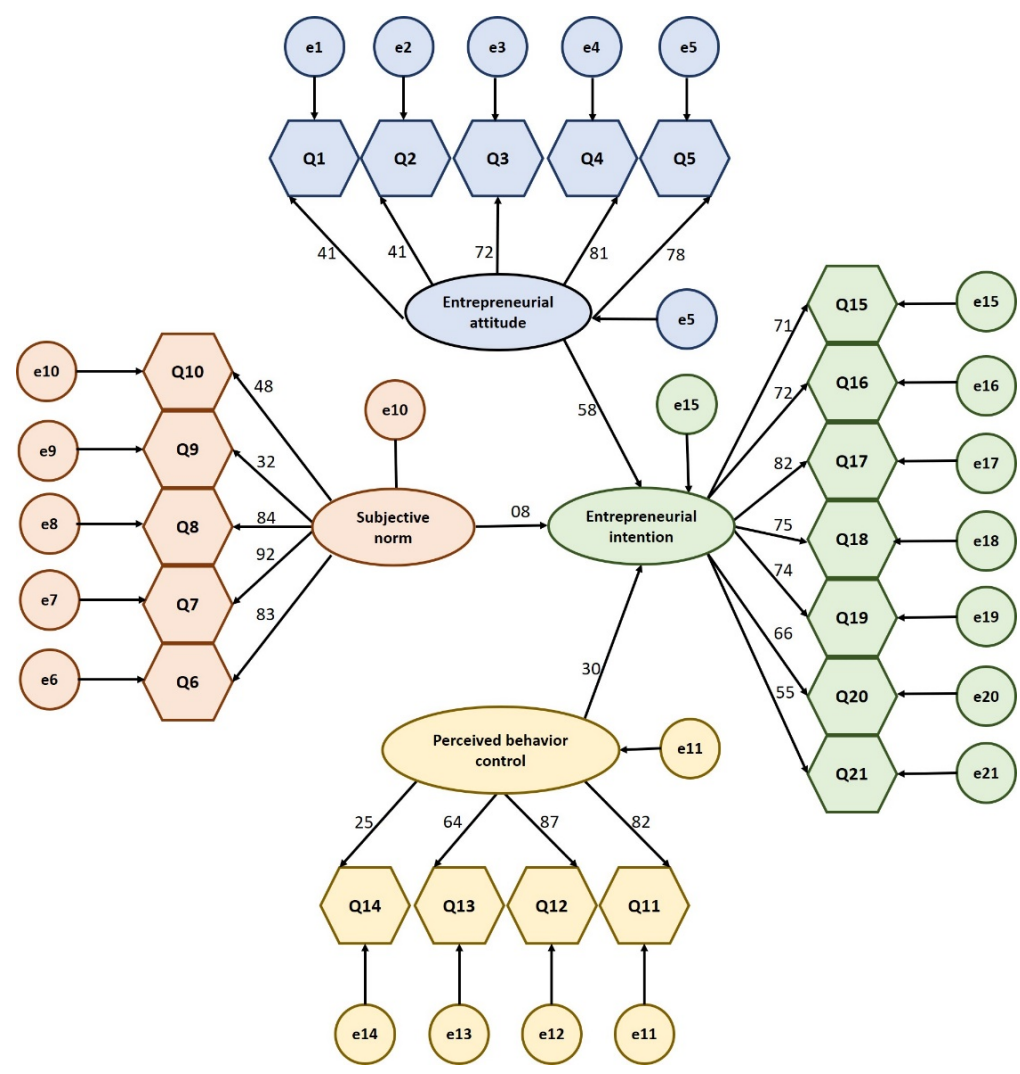

Fig. 5. The structure model of influencing factors of college students' innovation and entrepreneurial intention

This indicates that college students are more willing to get the support of close people in the IE motivation. Compared with indirect transitivity and external social environment, the support from family, friends and colleagues is more conducive to the occurrence of college students' IE behaviors. The measured variables of perceived behavior control also showed differentiated performance, such as Q12 (0.870), Q11 (0.819), and Q13 (0.641) with more significant impact, and Q14 (0.247) with weaker impact, indicating that in the process of college students' IE activities, the experience gained from personal experience is more conducive to the decision-making implementation than the experience gained by external perception. The measured variables of the entrepreneurial intention show an overall good significance in terms of the influence on latent variables, i.e., Q17 (0.820), Q18 (0.749), Q19 (0.737), Q16 (0.723), Q15 (0.711), Q20 (0.655), and Q21 (0.547). But it also follows the psychological cognition; the psychological self-cognition is positively correlated with psychological motivation and entrepreneurial intention. In summary, college students' IE education should not only be based on school education, but also consider the direct impact from society on IE intention. Therefore, the IE implementation process of 
college students should pay more attention to the practical experience of college students.

\section{$5 \quad$ Prospects for College Students' IE Education}

\subsection{Teaching strategy}

The model analysis found that college students' IE intention is affected by many factors. Therefore, the college students' IE education must also be implemented based on the theoretical knowledge of their psychological cognition and creative psychological development, and use certain teaching strategies so that it can play a good role in guiding the cultivation of IE spirit of college students. Combing the structural model and educational psychology, this paper makes the following suggestions.

Project grading and staged teaching for IE education: Creative knowledge in educational psychology shows that the psychological cognition of college students is the strongest, so it's necessary to use the college stage properly. When carrying out IE education, graded teaching should be made. i.e., construct the project from simple to complex, so that students first get a sense of self-identity, then enhance their ability to recognize innovation and entrepreneurship, and ultimately achieve product-based teaching. For example, first, when a student first attends a class, the student is allowed to define the course, and the teacher makes a positive evaluation; then, as the course progresses, the theoretical course is carried out while the students make designs for actual productization; in such graded and staged teaching process, students are given full play to their creative potential. Eventually, with the deepening of the curriculum, it can better cultivate the IE spirit of college students.

The school-enterprise joint education: Through the analysis for the latent variables such as entrepreneurial attitudes, perceived behavioral control, and entrepreneurial intention, it can be found that the significance of the students' intrinsic motivation has a great influence on the substantive education results of the IE. The implementation of school-enterprise joint education can not only allow students to learn theoretical knowledge, but also enable them to approach the entrepreneurs in person and feel the entrepreneurial spirit, and then gain direct experience, thereby achieving a deep understanding of innovation and entrepreneurship. Thus, it gradually positively promotes the cultivation of IE spirit while the entrepreneurs apply the theoretical knowledge to form the product of the project.

Identity education: The analysis of the subjective norms showed that the identity of family and friends has a great influence on the formation of college students' motivation for the IE. Therefore, education for students' sense of identity and no suppression will effectively promote the formation of college students' motivation for innovation and entrepreneurship, and then help them improve self-confidence and spirit in the process of project implementation. 


\subsection{Deficiencies and prospect}

Based on the educational psychology, this study focuses on the exploration of college students' motivation in IE education, without involving the optimal design of IE education, because in any education process, valuing education is the driving force to implement education, and the same is true for IE education. For instance, Menzies and Paradi [18] also pointed out in the study that there is a significant time lag effect between entrepreneurship education and individual entrepreneurial behavior, that is, after receiving entrepreneurial education, due to various reasons, individuals will accumulate and grow over time before starting a real business, and there is a considerable "time difference" between entrepreneurship education and entrepreneurial behavior. Zhang et al. [19] found through investigation that entrepreneurship education does have a significant impact on entrepreneurial intention. It can be seen that IE education has a subtle effect on the future growth and development of college students. Thus, future research will be further combined with educational practice, and the implementation process of IE education will be closely integrated in the process of exploring college students' psychological cognition.

\section{Conclusion}

As the third education pass, IE education for college students is attracting more and more attention around the world. Good IE education can effectively promote college students' understanding of employment and career selection. Therefore, IE education is not negligible in all major universities. This paper aims to explore the cultivation of the spirit of college students based on the TPB theoretical model and the creative knowledge of Zhang Dajun's educational psychology, and also obtain the influencing factors on the cultivation of IE spirit using the model calculations. On this basis, it further proposes the related feasible teaching strategy, with a view to provide effective help for the better development of IE education.

\section{$7 \quad$ Acknowledgement}

We really thank the financial support from the Colleges and universities in innovation and entrepreneurship education curriculum of Shaanxi (No.131, Design and implementation of college students' innovation and entrepreneurship projects), the seventh batch of key construction courses of Baoji University of Arts and Sciences (No.14, Innovation and entrepreneurship foundation), the research Program for Improving Public Scientific Quality of Shaanxi Provincial ((No. 75, Research on Coconstruction and Sharing of Popular Science Resources for Youth Based on the Trinity of College-Enterprise-Society), the Graduate Innovation Research Project of Baoji University of Arts and Sciences (YJSCX18YB05) and the National Innovation and Entrepreneurship Training Program for College Students (201910721007). 


\section{References}

[1] Gao, X.J., Cao, S.L. (2007). Innovation and Entrepreneurship Education_Cultivate the pioneers of the new era-A Summary of the Seminar on Innovation and Entrepreneurship Education of the Chinese Higher Education Society. China Higher Education Research, (7): 91-93. https://doi.org/10.4337/9781788972307.00014

[2] Li, P. (2010). Research on the Interactive Relationship between Entrepreneurship Education and Economic Development. Chinese \& Foreign Entrepreneurs, (14): 111-112.

[3] Gordon, I., Hamilton, E., Jack, S. (2012). A study of the regional economic development impact of a university led entrepreneurship education program me for small business owners. Entrepreneurship \& Regional Development, (24): 767-805. https://doi.org/10.10 $\underline{80 / 08985626.2011 .566377}$

[4] Clues, V.G.H. (1990). Continued experiment relating entrepreneurial education to students start-up decisions. Journal of small business management, 4: 45-53.

[5] Chen, B., Wu, J. (2019). Promotive effect of psychological intervention on English vocabulary teaching based on hybrid collaborative recommender technology, International Journal of Emerging Technologies in Learning, 14(15): 14-24. https://doi.org/10.3991/ijet. v14i15.11185

[6] Ajzen, I. (1991). The theory of planned behavior. Organizational behavior and human decision processes, 50(2), 179-211. https://doi.org/10.1016/0749-5978(91)90020-t

[7] Sun, L.Y. (2016). An Empirical Study on the Influencing Factors of University Stu-dents' Sustained Entrepreneurial Will_ Based on the Perspective of TPB Theory. Re-search in Educational Development, 36(21): 37-43. https://doi.org/10.14121/j.cnki.10083855.2016.21.008

[8] Zhang, A.H. (2019). Research on Guizhou college graduates' entrepreneurial will-ingness and influencing factors based on TPB theory. Guizhou University of Finance and Economics, 2019.

[9] Tyler, L. K., Ostrin, R. K., Cooke, M., \& Moss, H. E. (1995). Automatic Access of Lexical Information in Broca' s Aphasics: Against the Automaticity Hypothesis. Brain and Language, 48(2), 131-162. https://doi.org/10.1006/brln.1995.1007

[10] Qi, X., Liu, J.S. (2010). Research in the Influential Factors of University Students' De-sire of Founding an Undertaking on the Basis of TPB Mode. Journal of Anhui University of Technology (Social Sciences), 27(6): 163-165.

[11] Krueger, N.F., Reily, M.D., Carrud, A.L. (2000). Competing Models of Entrepreneurial Intentions. Journal of Business, (5-6): 411-432. https://doi.org/10.1016/S08839026(98)00033-0

[12] Shi, D.X. (2016). Situation and Determinants of Entrepreneurial Intentions of Students in College - The Empirical Analysis based on S University in Central Region of China. Review of Higher Education, 4(7): 18-26.

[13] Brenner, O.C., Pringle, C.D., Greenhaus, J.H. (1991). Perceived fulfillment of organization employment versus entrepreneurship: Work values and career intentions of business college graduates. Journal of Small Business Management, (3): 62-74.

[14] Mo, H. (2009). A path map of entrepreneurial intention in Chinese context_- Based on the theory of planed behavior. Science Research Management, 30(06): 128-135.

[15] Zou, T. (2018). Thoughts on the concept of innovation, entrepreneurship and education of colleges and universities based on the cultivation of positive psychological quality. Journal of Innovation and Enterprise Education, 9(5): 12-15. 10.3969/j.issn.1674-893X.2018. 05.005 
[16] National College Student Entrepreneurship Service Network [EB/OL]. [12.21]. https:// cy.ncss.cn/.

[17] Zhang, Y.Y. (2019). An investigation of college students' entrepreneurial intention and its influencing factors based on TPB theory-a case study of two medical colleges in Guangzhou. Guangzhou University of Chinese Medicine, 1-70. https://doi.org/10.27044/d. cnki.ggzzu.2019.000967

[18] Menzies, T.V., Paradi, J.C. (2003). Entrepreneurship education and engineering students career path and business performance. International Journal of Entrepreneur-ship and Innovation, 2003(02):121-132. https://doi.org/10.5367/000000003101299474

[19] Zhang, Y., Duysters, G., Cloodt, M. (2014). The role of entrepreneurship education as a predictor of university students' entrepreneurial intention. International Entrepreneurship and Management Journal, 10(3): 623-641. https://doi.org/10.1007/s11365-012-0246-Z

\section{Authors}

Lin Ma is a researcher, educator, and associate professor at Baoji University of Arts and Sciences, Baoji, in Shaanxi, China. She mainly conducts the development and evaluation of green lubricating materials, and research on innovation and entrepreneurship education.

Zhuangzhuang Lan, Bachelor of Arts and Science Bachelor of Education is currently studying, the main research direction is chemistry education.

Ru Tan is a graduate student of Baoji College of arts and sciences, majoring in chemistry and mainly studying the teaching direction of chemistry.

Article submitted 2020-05-01. Resubmitted 2020-05-28. Final acceptance 2020-05-28. Final version published as submitted by the authors. 